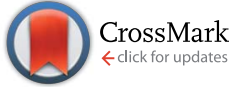

Cite this: RSC Adv., 2015, 5, 46307

\title{
Designing temperature-memory effects in semicrystalline polyurethane $\uparrow$
}

\begin{abstract}
Nikolaus Mirtschin and Thorsten Pretsch*
Temperature-memory polymers are able to generate a substantial mechanical response when heated above the temperature, at which a preceding deformation was carried out. Here we show how to design the temperature-memory effect (TME) by thermomechanical treatment. As a model polymer, phase segregated poly(ester urethane) (PEU) containing crystallizable segments of poly(1,4-butylene adipate) (PBA) was used. For programming, strain elongation was applied at temperatures within the PBA melting transition area, before temperature holding, unloading and cooling were carried out. Upon heating under stress-free or constant strain recovery conditions, precisely set temperature-memory onsets could be witnessed. Most importantly, strain fixities and recoverabilities the same as maximum recovery stresses turned out to be controllable by strain rate and temperature holding time after deformation, while transition temperatures remained largely unaffected. The tailoring of thermoresponsiveness was structurally enabled by different PBA crystallinities in the programmed state as verified by wide-angle Xray scattering (WAXS). The reported studies intend to design TMEs in semicrystalline polyurethanes according to user-defined needs to make this technology broadly applicable.
\end{abstract}

Received 27th March 2015

Accepted 15th May 2015

DOI: $10.1039 / \mathrm{c} 5 \mathrm{ra05492c}$

www.rsc.org/advances

release of stored mechanical energy as determined by the relaxation behavior of the macromolecules. ${ }^{29-31}$ Once a polymer is identified as "high performance" TMP, optimization in chemical structure as frequently witnessed for $\operatorname{SMPs}^{32,33}$ is no longer necessary.

Today, technological potential resides for TMPs in applications like self-sufficient release systems, ${ }^{3}$ temperature sensors, ${ }^{34}$ instruments for minimally invasive surgery ${ }^{35}$ and switchable information carriers. ${ }^{36} \mathrm{Up}$ to now, a wide range of polymer design concepts proved to be sustainable. Temperature-memory behavior could be verified for amorphous polymer systems, including polyvinyl alcohol-based nanocomposites, ${ }^{1,37}$ perfluorosulfonic acid ionomer (Nafion), ${ }^{34,38,39}$ poly(ether urethane) and radio opaque composites thereof ${ }^{40}$ semi-interpenetrating poly(methyl methacrylate)/poly(ethylene glycol) (PMMA/PEG) networks ${ }^{5,41}$ covalently cross-linked PMMA-poly( $\varepsilon$-caprolactone) (PMMA-PCL),${ }^{5}$ miscible poly(L-lactide)/PMMA blends, ${ }^{42}$ polyamide 12 and polyamide microfibers loaded with multiwall carbon nanotubes ${ }^{43}$ and acrylate-based polymer. ${ }^{6}$ It is remarkable that only few semicrystalline polymers qualified as versatile TMPs so far. These include poly[ethylene-ran-(vinyl acetate)] copolymers with crystallizable polyethylene segments, ${ }^{3}$ poly(ester urethanes) (PEU) containing crystallizable PCL segments, ${ }^{35}$ photo-cross-linked star PCL-PEG networks ${ }^{4}$ and PEU with crystallizable poly(1,4-butylene adipate) (PBA). ${ }^{36}$

Surprisingly, studies reporting on a tailoring of temperature-

BAM Federal Institute for Materials Research and Testing, Division 6.5, Polymers in Life Science and Nanotechnology, Unter den Eichen 87, 12205 Berlin, Germany. E-mail: thorsten.pretsch@bam.de; Fax: +49 308104 1617; Tel: +49 3081043804

$\dagger$ Electronic supplementary information (ESI) available. See DOI: memory properties by variation of programming conditions are rare. In well-designed experiments on poly(ether urethane) and its radio opaque composites, the application of higher 
maximum strains, for instance, gave increased recovery stresses. ${ }^{40}$ Moreover, Nafion could be identified as fruitful example for programming-assisted control of thermoresponsiveness. In this case, shape fixing was carried out in a strain- and stress-controlled manner and control over maximum recovery speed could be achieved when applying a targeted strain. ${ }^{34}$ In another significant parametric study, the free recovery behavior of amorphous acrylate-based polymer was examined. ${ }^{6}$ Herein, decreasing the heating rate was identified to increase the recovery speed versus the recovery temperature, and it was theoretically predicted that increasing the temperature holding time after deformation will decrease the recovery speed. Apart from that, Grillard et al. ${ }^{\mathbf{4 3}}$ found out that fibers made of polyamide 12 loaded with multiwall carbon nanotubes (CNT-PA12 composite fibers) lose temperaturememory when slowly deformed in the course of programming or when kept for more than $10 \mathrm{~min}$ at elevated temperatures. The associated loss of recovery stress was explained with the relaxation of dynamic heterogeneities, which were present in the glassy domains of the examined systems. This motivated us to investigate the influence of time-dependent programming steps on the temperature-memory behavior of a semicrystalline polymer for the first time. To address this, a PEU with distinct temperature-memory properties was selected and a recently introduced method for temperature-memory onset programming $^{36}$ selectively modified by varying the strain rate and temperature holding time after deformation. Once programmed, the thermoresponsiveness was investigated both under stress-free and constant strain recovery conditions. Against this background we demonstrate that a careful parameter selection constitutes a useful way to control the temperature-memory behavior of the PEU. This way an approach was followed, which goes far beyond recent attempts to set temperature-memory transitions in semicrystalline TMPs. ${ }^{3,4,35}$ Compared with CNT-PA12 composite fibers, ${ }^{43}$ widely differing programming/temperature-memory relations could be witnessed.

\section{Experimental section}

\subsection{Materials}

The herein investigated TMP was Desmopan DP 2795A SMP, which is a poly(ester urethane) (PEU) from Bayer MaterialScience AG. Samples were received as $2 \mathrm{~mm}$ thick injection molded plaques. The hard segment was composed of $4,4^{\prime}$ methylenediphenyl diisocyanate (MDI) and a 1,4-butanediol (BD) chain extender. The soft segment was built up by poly $(1,4-$ butylene adipate) (PBA) characterized by a molecular weight of $3500 \mathrm{~g} \mathrm{~mol}^{-1}$. The thermal properties of the PBA phase including calorimetric studies and dynamic mechanical analysis were previously reported. ${ }^{36}$ Further information regarding the molecular structure of the PEU, an attenuated total reflectance-Fourier transform-infrared (ATR-FT-IR) spectrum with signal assignment and wide-angle X-ray scattering (WAXS) data, confirming the presence of crystalline PBA units in the PEU at $23{ }^{\circ} \mathrm{C}$, were also recently supplied. ${ }^{36}$ The mean hardness of the PEU changes from approximately 92 Shore A at $23{ }^{\circ} \mathrm{C}$ to 62
Shore A at $60{ }^{\circ} \mathrm{C}^{\mathbf{4 4}}$ Apart from that, Desmopan DP 2795A SMP is characterized by good shape-memory properties (ESI Fig. $1 \dagger$ ) and proved to be well-suited for the preparation of information carriers. ${ }^{45-48}$

\subsection{Characterization methods}

Thermomechanical measurements were conducted with an electromechanical testing system (Zwick/Roell Z005), which was equipped with a thermochamber (Zwick/Roell) and a temperature controller (Eurotherm 2261e). Test procedures were designed with the software testXpert ${ }^{\circledR}$ II (V 3.31). For specimen preparation, type $5 \mathrm{~B}$ tensile bars ${ }^{49}$ were punched out of the PEU plaques. Prior usage, specimens were annealed for $10 \mathrm{~min}$ at $60{ }^{\circ} \mathrm{C}$ and stored for at least one week at $23{ }^{\circ} \mathrm{C}(50 \%$ air humidity). At the beginning of a measurement, a tensile bar was clamped with an initial gauge length of $10 \mathrm{~mm}$ into the pneumatic grips of the electromechanical testing system. Typically, a clamping pressure of 5.2 bar was selected. In the course of thermomechanical measurements, changes in normal force were followed with a $100 \mathrm{~N}$ load cell. In parallel, the stress $\sigma$ was determined by dividing the force through the initial cross section of the specimen. During each measurement, changes in strain $\varepsilon$ were followed from crosshead displacement.

To program temperature-memory onsets into PEU, specimens were initially cooled or heated from $23{ }^{\circ} \mathrm{C}$ to the deformation temperature $T_{\mathrm{d}}=-10,0,10,20,30$ and $40{ }^{\circ} \mathrm{C}$. Adjacently, different programming approaches were followed and the temperature-memory behavior was examined. In the first scenario, a maximum strain $\varepsilon_{\mathrm{m}}$ of $100 \%$ was applied with a strain rate $\varepsilon^{\prime}$ of $1 \% \mathrm{~min}^{-1}$ or $3 \times 10^{4} \% \mathrm{~min}^{-1}$. In the obtained stress-strain diagram, the Young's modulus $E$ was calculated from the initial slope as ratio of stress to strain. The yield point including the associated strain $\varepsilon_{\mathrm{y}}$ and stress $\sigma_{\mathrm{y}}$ was determined from the early local maximum in the stress-strain curves. In those cases where no local maximum occurred, the two tangent intersection method was used to estimate the onset of plastic deformation. ${ }^{50}$ After $5 \mathrm{~min}$ at $T_{\mathrm{d}}$, the specimen was unloaded with a rate of $10 \% \mathrm{~min}^{-1}$ before it was finally cooled to $-20{ }^{\circ} \mathrm{C}$.

In the other programming series, the temperature holding time $t_{\mathrm{h}}$ after deformation was varied. For this purpose, a strain rate of $3 \times 10^{2} \% \mathrm{~min}^{-1}$ was selected while $\varepsilon_{\mathrm{m}}$ was set to $100 \%$ and $t_{\mathrm{h}}$ to $5 \mathrm{~min}$ or $15 \mathrm{~h}$. To finalize programming, the specimen was unloaded at $T_{\mathrm{d}}$ and cooled to $-20{ }^{\circ} \mathrm{C}$, where the fixed strain $\varepsilon_{\mathrm{u}}$ was determined.

Independent of the programming method, thermoresponsiveness was adjacently studied under stress-free and constant strain recovery conditions. Therefore, specimens were heated from -20 to $80{ }^{\circ} \mathrm{C}$. In case of free strain recovering, the strain $\varepsilon_{\mathrm{p}}$ characterizing the recovered shape was determined. Additionally, the recovered strain $\varepsilon_{\mathrm{u}}-\varepsilon_{\mathrm{p}}$ was quantified. The strain fixity ratio $R_{\mathrm{f}}$ and the total strain recovery ratio $R_{\mathrm{r} \text {,tot }}$ were calculated according eqn (1) and (2):

$$
R_{\mathrm{f}}=\frac{\varepsilon_{\mathrm{u}}}{\varepsilon_{\mathrm{m}}}
$$




$$
R_{\mathrm{r}, \mathrm{tot}}=\frac{\varepsilon_{\mathrm{m}}-\varepsilon_{\mathrm{p}}}{\varepsilon_{\mathrm{m}}}
$$

To precisely characterize the switching transitions, tangent lines were established in the recovery curve of the straintemperature test protocol. The temperatures corresponding to their intersection points at the beginning and toward the end of heating were defined as on- and offset switching temperature $T_{\text {sw,on }}$ and $T_{\text {sw,off }}$, respectively.

When examining the stress recovery behavior, the maximum recovery stress $\sigma_{\max }$ was determined. For a detailed analysis, tangent lines were established in the stress-temperature test protocol. Those temperatures, which corresponded to their intersection points at the beginning and toward the end of heating, were defined as on- and offset stress recovery temperature $T_{\sigma, \text { on }}$ and $T_{\sigma, \text { off }}$.

Infrared (IR) thermography was used to follow the temperature distribution on the surface of a PEU specimen during elongation at $T_{\mathrm{d}}=20^{\circ} \mathrm{C}$. For this experiment a strain rate of $3 \times$ $10^{4} \% \mathrm{~min}^{-1}$ and an elongation of $100 \%$ were selected. The temperature was recorded with a microbolometer IR camera VarioCAM ${ }^{\circledR} \mathrm{hr}$ from InfraTec, which operated in a spectral range of 7.5-14.0 $\mu \mathrm{m}$ and was equipped with a close-up lens, which had a resolution of $50 \mu \mathrm{m}$. The camera was placed at a distance of less than $10 \mathrm{~mm}$ from the specimen. The emissivity of PEU surface was set to 1 . Thermal data was recorded using a frame rate of $50 \mathrm{~Hz}$ and an array size of $640 \times 480$ pixel.

In situ wide-angle X-ray scattering (WAXS) was performed at the synchrotron microfocus beamline " $\mu$ Spot" at Bessy II (Helmholtz Centre Berlin for Materials and Energy). The employed diffraction setup was identical with the one described by Paris et $a l .{ }^{51}$ The experiments were carried out at a wavelength of $1 \AA$ and an exposure time of $15 \mathrm{~s}$. A two-dimensional Xray detector (MarMosaic, CCD $3072 \times 3072$ ) was used to collect the scattered radiation at a distance of $170 \mathrm{~mm}$ behind the specimen. A temperature controlled sample holder unit TCS 120 (Anton Paar, Austria), equipped with a Peltier heater and a Pt 100 temperature sensor, was used for heating. Initially, a pristine PEU specimen was cut at $8{ }^{\circ} \mathrm{C}$ to a length of $13 \mathrm{~mm}$ and loosely attached to the precooled sample holder. Subsequently, the specimen was heated from 8 to $60{ }^{\circ} \mathrm{C}$ using a rate of $3{ }^{\circ} \mathrm{C}$ $\min ^{-1}$. In parallel, scattering images were recorded. The computer program FIT2D ${ }^{52}$ was employed to obtain diagrams of scattered intensities versus scattering angle $2 \theta$ (with respect to the wavelength of the $\mathrm{Cu} \mathrm{K} \alpha$-line). The degree of PEU crystallinity $\chi_{\mathrm{c}}$ was estimated from the obtained WAXS patterns by dividing the integrated intensity due to scattering from crystallites $I_{\text {cryst }}$ through the totally scattered intensity $I_{\text {total }}$ :

$$
\chi_{\mathrm{c}}=\frac{I_{\text {cryst }}}{I_{\text {total }}}
$$

Furthermore, various specimens were examined by means of WAXS directly after programming $\left(T_{\mathrm{d}}=10^{\circ} \mathrm{C}: \varepsilon^{\prime}=1 \% \mathrm{~min}^{-1}\right.$ or $3 \times 10^{4} \% \min ^{-1} ; T_{\mathrm{d}}=10$ or $40{ }^{\circ} \mathrm{C}: \varepsilon^{\prime}=3 \times 10^{2} \% \min ^{-1}$ and $t_{\mathrm{h}}=$ $5 \mathrm{~min}$ or $15 \mathrm{~h}$ ). Again, the same setup as described above was used and a testing temperature of $10{ }^{\circ} \mathrm{C}$ selected.

\section{Results and discussion}

One criterion which qualifies phase segregated, semicrystalline polymer networks like PEUs as versatile TMPs is that the soft (mobile) phase is characterized by a broad thermal transition. ${ }^{36}$ This motivated us to start our examinations with in situ WAXS on a model PEU, herein used as TMP (Fig. 1). The transition associated with the melting of the poly(1,4-butylene adipate) (PBA) phase was found to spread from $10{ }^{\circ} \mathrm{C}\left(\chi_{\mathrm{c}}=12.2 \%\right)$ to $56{ }^{\circ} \mathrm{C}$. The overall crystallinity of the PEU was dominated by the soft segment. In the WAXS patterns, only one weak signal at $2 \theta=21.3^{\circ}$ could be identified which remained unaffected by temperature variation and therefore seemed to derive from the hard segment (ESI Fig. $2 \dagger$ ).

Subsequently, thermomechanical treatment was applied as essential part of programming TMEs (Fig. 2). The whole programming history is exhibited in Fig. 2a. Initially, PEU specimens were tensile loaded at different deformation temperatures $T_{\mathrm{d}}$ using strain rates $\varepsilon^{\prime}$ of $1 \% \mathrm{~min}^{-1}$ and $3 \times 10^{4} \%$ $\min ^{-1}$, respectively. The stress-strain behavior was followed, first of all, until specimens were unloaded (Fig. 2b-d and ESI Fig. $3 \dagger$ ). According to the evolution of Young's modulus $E$, material stiffness increased at lower $T_{\mathrm{d}}$ (see caption of Fig. 2). This had been expected from the rising crystallinity content in the pre-deformation states (Fig. 1). In turn, the elasticity of the material decreased at lower temperatures (ESI Fig. $3 \dagger$ ) as suggested by a contemporaneous decrease in strain at yield (ESI Fig. $3 \mathrm{a} \dagger$ ) and increase in stress at yield (ESI Fig. 3b $\dagger$ ). One can also notice that elasticity depended on strain rate as exemplified by consistently lower strains and stresses at yield when applying slow deformation (ESI Fig. $3 \dagger$ ). Further, it is apparent that the tensile stress required to elongate the specimens to $\varepsilon_{\mathrm{m}}=100 \%$ systematically increased at lower $T_{\mathrm{d}}$. In this context, a steady growth in deformation resistance was found in the stress-strain plots of slow deformation, which became steeper at higher elongations. This effect intensified at lower temperatures and can be explained with the occurrence of material hardening through strain-induced PBA crystallization. ${ }^{53}$ Moreover, necking took place after rapid deformation at $T_{\mathrm{d}} \leq 20{ }^{\circ} \mathrm{C}$ as already witnessed for other urethane-based polymers. ${ }^{54,55}$ Since neck formation and propagation in polymers can be accompanied with heat generation ${ }^{56-58}$ - the interrelation of temperature rise

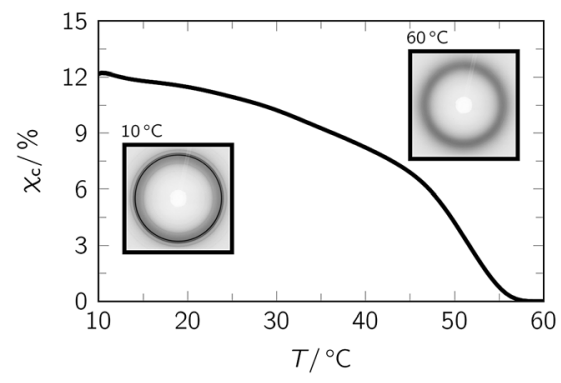

Fig. 1 Evolution of overall crystallinity $\chi_{c}$ when heating pristine PEU during an in situ WAXS measurement. The insets show the diffractograms at the beginning and end of the measurement. 
(a)

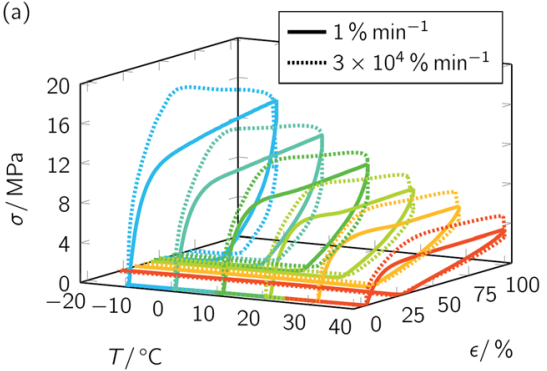

(c)

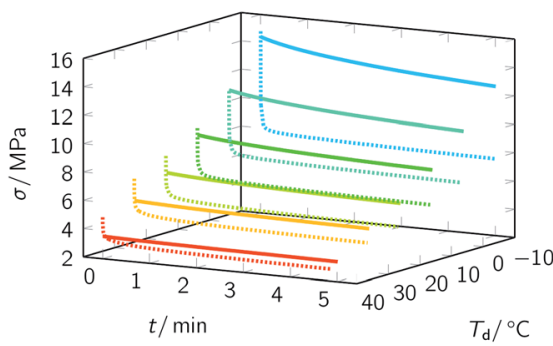

(b)

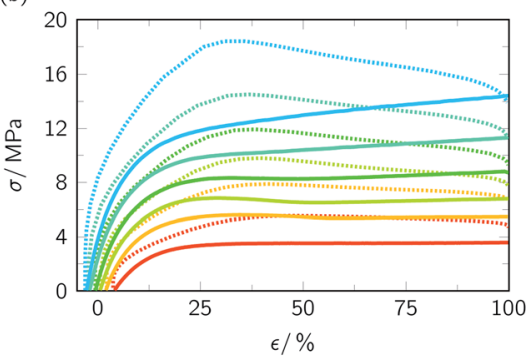

(d)

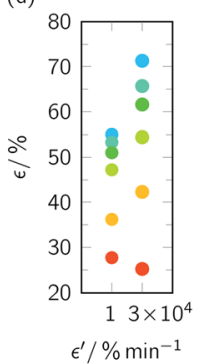

Fig. 2 Programming of various temperature-memory effects in PEU. Stress-strain-temperature protocol (a) and diagrams showing the stressstrain behavior during deformation ((b), strain rate $\varepsilon^{\prime}=1 \% \mathrm{~min}^{-1}$ and $\left.3 \times 10^{4} \% \mathrm{~min}^{-1}\right)$, stress relaxation behavior when keeping the specimens at $\varepsilon_{\mathrm{m}}=100 \%$ (c) and nominal strain after unloading with $10 \% \mathrm{~min}^{-1}$ at $T_{\mathrm{d}}$ (d). For $\varepsilon^{\prime}=1 \% \mathrm{~min}^{-1}$, Young's moduli $E$ of $166 \mathrm{MPa}\left(T_{\mathrm{d}}=-10{ }^{\circ} \mathrm{C}\right), 131 \mathrm{MPa}$ $\left(T_{d}=0{ }^{\circ} \mathrm{C}\right), 114 \mathrm{MPa}\left(T_{\mathrm{d}}=10^{\circ} \mathrm{C}\right), 96 \mathrm{MPa}\left(T_{\mathrm{d}}=20^{\circ} \mathrm{C}\right), 78 \mathrm{MPa}\left(T_{\mathrm{d}}=30^{\circ} \mathrm{C}\right)$ and $43 \mathrm{MPa}\left(T_{\mathrm{d}}=40^{\circ} \mathrm{C}\right)$ were determined.

with stretching was discovered by Gough when studying caoutchouc $^{59}$ - we decided to extend our investigations toward infrared thermography by exemplarily following the specimen temperature at its surface during elongation at $20^{\circ} \mathrm{C}$ (Fig. 3). With regard to the obtained image series it can be seen that two necks developed simultaneously at a strain of about $40 \%$ and thus beyond the maximum of the corresponding stress-strain curve (see dotted, pastel green line in Fig. 2b). The observed behavior is commonly favored in polymers by high extension rates and sometimes referred to secondary or double necking. ${ }^{60}$ In the course of rapid elongation, portion of the work expended on deformation started transforming into heat. Shortly after finalizing the deformation process, the highest temperature was recorded in the necking regions, illustrating a temperature increase with reference to the specimen's pre-deformation state by approximately $6{ }^{\circ} \mathrm{C}$.

Anyway, to continue with the programming of TMEs, loaded specimens were exposed to a 5 min temperature holding step at
$T_{\mathrm{d}}$ while the elongation was maintained. During this time, stress relaxed significantly, but less strongly when loading was carried out with the lower strain rate (Fig. 2c). The reason is that PBA crystals, which derived from the pre-deformation state, and further PBA crystals, which formed in the course of elongation (a sufficient thermal stability is assumed), counteracted the recovering of the specimens. By contrast, much stronger stress declines were witnessed during temperature holding subsequent to rapid deformation (Fig. 2c), culminating in lower stresses before unloading (ESI Fig. $4 \dagger$ ). Obviously, some PBA crystals, which were present in the pre-deformation states, were molten and could no longer serve as physical cross-links. However, we conjecture that briefly after deformation significant crystallization occurred at $T_{\mathrm{d}}$. This could explain the in tendency higher strains after unloading compared with those detected after slow deformation (Fig. 2d). To prove our assumption, WAXS measurements were carried out on programmed PEU, which was deformed at $10^{\circ} \mathrm{C}$ with slow and high
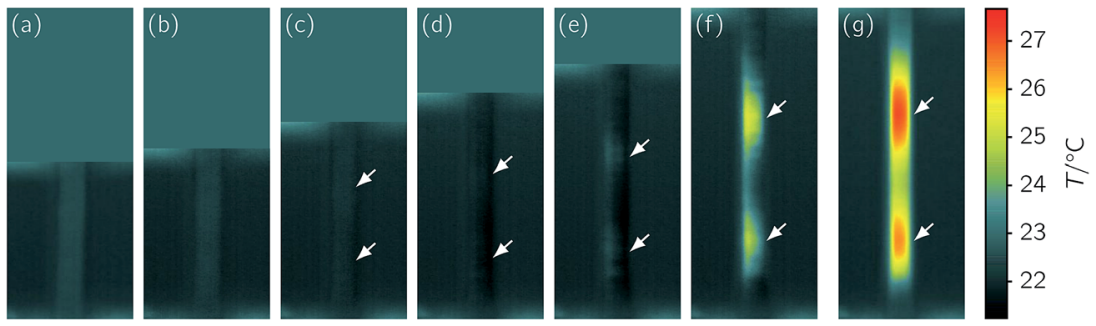

Fig. 3 Sequence of thermographic images recorded at $20{ }^{\circ} \mathrm{C}$ during elongation $\left(\varepsilon^{\prime}=3 \times 10^{4} \% \mathrm{~min}^{-1}\right.$, (a-f)) and $1.1 \mathrm{~s}$ after stretching (g) a PEU specimen. The corresponding strain values were $0 \%$ (a), $20 \%$ (b), $40 \%$ (c), $60 \%$ (d), $80 \%$ (e) and $100 \%$ (f and g). The formation of an upper and a lower neck is illustrated by the arrows. 
(a)

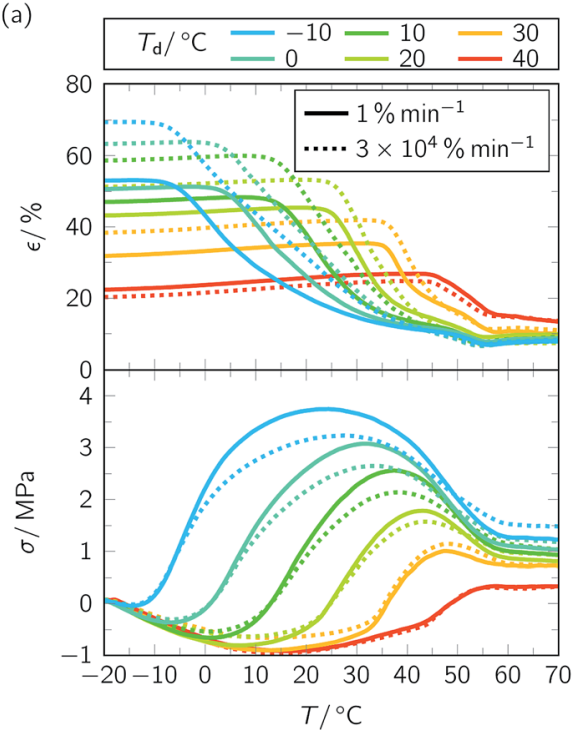

(b)

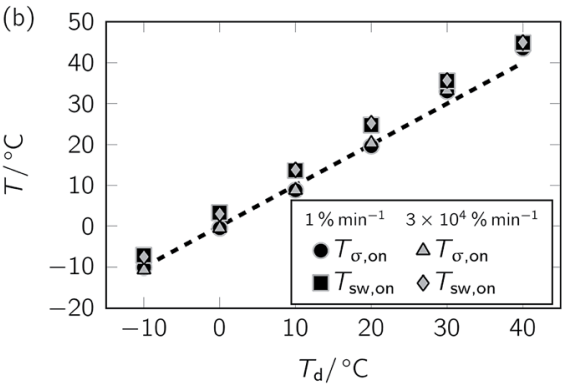

Fig. 4 Influence of strain rate $\varepsilon^{\prime}$ on temperature-memory behavior of $\operatorname{PEU}\left(\varepsilon_{\mathrm{m}}=100 \%\right)$. Consideration of $\varepsilon^{\prime}=1 \% \mathrm{~min}^{-1}$ (solid lines) and $\varepsilon^{\prime}=3$ $\times 10^{4} \% \mathrm{~min}^{-1}$ (dotted lines). Results of stress-free and constant strain recovery measurements (a) and evolution of $T_{s w, o n}$ and $T_{\sigma, o n}$ with $T_{\mathrm{d}}(\mathrm{b})$.

strain rate while the other thermomechanical parameters remained unchanged (ESI Fig. $5 \dagger$ ). The analysis of the WAXS diffractograms gave evidence that strain rate had an impact on the overall crystallinity $\chi_{\mathrm{c}}$. When deforming the specimen more rapidly $\left(\varepsilon^{\prime}=3 \times 10^{4} \% \mathrm{~min}^{-1}\right)$, a $\chi_{\mathrm{c}}$ of $20.5 \%$ was determined; in turn, it was $17.2 \%$ when choosing a lower strain rate $\left(\varepsilon^{\prime}=1 \% \min ^{-1}\right)$. To further confirm that time-dependent programming steps were affecting the thermomechanical behavior, the total time at which specimens were kept at $T_{\mathrm{d}}$ was varied by modifying the unloading rate, and the influence on residual strains was determined. As a matter of fact, a $T_{\mathrm{d}}$ of $-10{ }^{\circ} \mathrm{C}$ and a strain rate of $3 \times 10^{4} \% \mathrm{~min}^{-1}$ were selected, the temperature holding step after deformation was omitted and specimens were unloaded with different rates before they were cooled to $-20{ }^{\circ} \mathrm{C}$. In accordance with the above obtained picture, it became obvious that nominal strain gradually increased with decelerating unloading rate and thus with progressing storage time at $T_{\mathrm{d}}\left(1 \times 10^{4} \% \mathrm{~min}^{-1}: 43 \% ; 3 \times 10^{3} \%\right.$ $\min ^{-1}: 45 \% ; 3 \times 10^{2} \% \min ^{-1}: 56 \% ; 10 \% \min ^{-1}: 66 \%$ ). Again, growing PBA crystallinity seemingly supported a remarkable enhancement in fixed strain.

To study the influence of strain rate on temperature-memory behavior under stress-free and constant strain recovery conditions, the specimens whose thermomechanical treatment is shown in Fig. 2 were heated to $80{ }^{\circ} \mathrm{C}$ (Fig. 4, Table 1). Taking a closer look at the data illustrates that thermomechanical properties were largely depending on programming. At the 30000 times higher strain rate, progressive PBA crystallization after specimen drawing substantiated a higher strain fixity ratio $R_{\mathrm{f}}$ (Table 1). Under stress-free recovery conditions, larger fixed strain inevitably resulted in enhanced recovery strain $\varepsilon_{\mathrm{u}}-\varepsilon_{\mathrm{p}}$, which impressively demonstrates an adjustability of the most relevant thermomechanical parameters through strain rate variation. This way, it could be shown that manipulation of the stress-free recovery behavior of TMPs is not restricted to the variation of programming parameters like $\varepsilon_{\mathrm{m}}{ }^{40}$ or cooling conditions after deformation. ${ }^{6,34}$ However, an exception was the $T_{\mathrm{d}}=40{ }^{\circ} \mathrm{C}$ scenario (Table 1, Fig. $4 \mathrm{a}$, above). Here, the PBA phase had its lowest pre-deformation crystallinity and no clear influence of strain rate on temperature-memory properties could be found. Regarding the maximum recovery stress $\sigma_{\max }$, the influence of strain rate was almost negligible for $T_{\mathrm{d}}=30$ and $40{ }^{\circ} \mathrm{C}$. In contrast, systematically lower $\sigma_{\max }$ values were determined upon rapid deformation for $T_{\mathrm{d}} \leq 20^{\circ} \mathrm{C}$ (Table 1, Fig. 4a, below). In the first instance, this behavior was unexpected, because PBA crystallinity seemed to be higher, and motivated us

Table 1 Influence of strain rate on temperature-memory properties of PEU ( $\left.\varepsilon_{\mathrm{m}}=100 \%\right)$. Errors were estimated from repeated measurements

\begin{tabular}{|c|c|c|c|c|c|c|c|c|c|c|}
\hline \multirow[b]{2}{*}{$T_{\mathrm{d}}\left({ }^{\circ} \mathrm{C}\right)$} & \multirow[b]{2}{*}{$\varepsilon^{\prime}\left(\% \min ^{-1}\right)$} & \multirow[b]{2}{*}{$R_{\mathrm{f}}(\%)$} & \multicolumn{4}{|c|}{ Stress-free recovery conditions } & \multicolumn{4}{|c|}{ Constant strain recovery conditions } \\
\hline & & & $R_{\mathrm{r}, \text { tot }}(\%)$ & $\varepsilon_{\mathrm{u}}-\varepsilon_{\mathrm{p}}(\%)$ & $T_{\mathrm{sw}, \text { on }}\left({ }^{\circ} \mathrm{C}\right)$ & $T_{\mathrm{sw}, \text { off }}\left({ }^{\circ} \mathrm{C}\right)$ & $T_{\sigma, \mathrm{on}}\left({ }^{\circ} \mathrm{C}\right)$ & $T_{\sigma, \max }\left({ }^{\circ} \mathrm{C}\right)$ & $T_{\sigma, \text { off }}\left({ }^{\circ} \mathrm{C}\right)$ & $\sigma_{\max }(\mathrm{MPa})$ \\
\hline-10 & 1 & $53 \pm 2$ & $91 \pm 2$ & $44 \pm 2$ & $-7 \pm 1$ & $55 \pm 2$ & $-10 \pm 2$ & $24 \pm 2$ & $57 \pm 2$ & $3.7 \pm 0.2$ \\
\hline 0 & 1 & $51 \pm 2$ & $91 \pm 2$ & $42 \pm 2$ & $3 \pm 1$ & $55 \pm 2$ & $-1 \pm 2$ & $32 \pm 2$ & $56 \pm 2$ & $3.1 \pm 0.2$ \\
\hline 10 & 1 & $47 \pm 2$ & $91 \pm 2$ & $38 \pm 2$ & $14 \pm 1$ & $55 \pm 2$ & $9 \pm 2$ & $37 \pm 2$ & $57 \pm 2$ & $2.6 \pm 0.2$ \\
\hline 20 & 1 & $43 \pm 2$ & $90 \pm 2$ & $33 \pm 2$ & $25 \pm 1$ & $54 \pm 2$ & $20 \pm 2$ & $43 \pm 2$ & $57 \pm 2$ & $1.8 \pm 0.2$ \\
\hline 30 & 1 & $32 \pm 2$ & $91 \pm 2$ & $23 \pm 2$ & $36 \pm 1$ & $55 \pm 2$ & $33 \pm 2$ & $48 \pm 2$ & $58 \pm 2$ & $1.0 \pm 0.2$ \\
\hline 40 & 1 & $22 \pm 2$ & $88 \pm 2$ & $10 \pm 2$ & $45 \pm 1$ & $57 \pm 2$ & $44 \pm 2$ & $57 \pm 2$ & $61 \pm 2$ & $0.3 \pm 0.2$ \\
\hline-10 & $3 \times 10^{4}$ & $70 \pm 2$ & $92 \pm 2$ & $62 \pm 2$ & $-8 \pm 1$ & $53 \pm 2$ & $-11 \pm 2$ & $27 \pm 2$ & $59 \pm 2$ & $3.2 \pm 0.2$ \\
\hline 0 & $3 \times 10^{4}$ & $63 \pm 2$ & $92 \pm 2$ & $55 \pm 2$ & $3 \pm 1$ & $52 \pm 2$ & $-1 \pm 2$ & $34 \pm 2$ & $58 \pm 2$ & $2.7 \pm 0.2$ \\
\hline 10 & $3 \times 10^{4}$ & $59 \pm 2$ & $90 \pm 2$ & $49 \pm 2$ & $14 \pm 1$ & $53 \pm 2$ & $9 \pm 2$ & $38 \pm 2$ & $58 \pm 2$ & $2.1 \pm 0.2$ \\
\hline 20 & $3 \times 10^{4}$ & $51 \pm 2$ & $92 \pm 2$ & $43 \pm 2$ & $25 \pm 1$ & $54 \pm 2$ & $20 \pm 2$ & $43 \pm 2$ & $59 \pm 2$ & $1.6 \pm 0.2$ \\
\hline 30 & $3 \times 10^{4}$ & $38 \pm 2$ & $89 \pm 2$ & $27 \pm 2$ & $36 \pm 1$ & $55 \pm 2$ & $33 \pm 2$ & $48 \pm 2$ & $59 \pm 2$ & $1.2 \pm 0.2$ \\
\hline 40 & $3 \times 10^{4}$ & $20 \pm 2$ & $87 \pm 2$ & $7 \pm 2$ & $45 \pm 1$ & $56 \pm 2$ & $44 \pm 2$ & $57 \pm 2$ & $61 \pm 2$ & $0.3 \pm 0.2$ \\
\hline
\end{tabular}



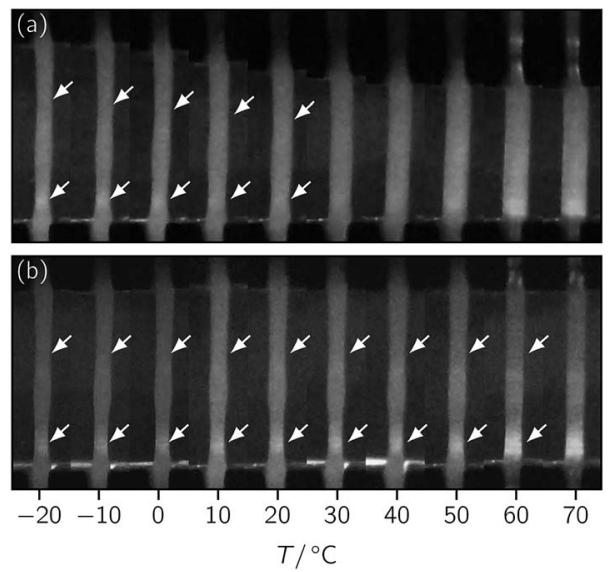

Fig. 5 Thermoresponsiveness of programmed PEU specimens $\left(T_{d}=\right.$ $\left.-10{ }^{\circ} \mathrm{C}, \varepsilon^{\prime}=3 \times 10^{4} \% \mathrm{~min}^{-1}, \varepsilon_{\mathrm{m}}=100 \%\right)$ under stress-free recovery conditions (a) and constant strain recovery conditions (b). The position of the upper and lower neck is illustrated by the arrows.

to study the recovery of the necks. Intriguingly, local reversion of the necking processes could be observed both under stressfree and constant strain recovery conditions for specimens, which were deformed at $-10{ }^{\circ} \mathrm{C}$ (Fig. 5). As visible to the naked eye, neck recovering was finalized under stress-free conditions somewhere in the middle of the switching transition (Fig. 5a, also compare Fig. 4a). In turn, the upper and lower neck recovered under constant strain conditions at a significantly higher temperature, which was well above $T_{\sigma, \max }$ and close to $T_{\sigma, \text { off }}$ (Table 1, Fig. 5b). Since no necking could be detected after slow elongation, the necks observed after rapid elongation at $T_{\mathrm{d}}$ $\leq 20^{\circ} \mathrm{C}$ and their slow recovering give a reasonable explanation for a lowering in maximum recovery stress (Table 1, Fig. 4a, below). Nevertheless, satisfying the criterion of temperaturememory behavior, transition temperatures $\left(T_{\mathrm{sw}, \mathrm{on}}, T_{\sigma, \mathrm{on}}\right)$ increased linearly with $T_{\mathrm{d}}$ (Fig. $4 \mathrm{~b}$ ) and the temperature regime of responsiveness remained unaffected by strain rate. Furthermore, temperatures corresponding to $\sigma_{\max }$ did not shift when varying the strain rate (Fig. $4 \mathrm{a}$, below). This way, a more stable material behavior could be detected for PEU compared with CNT-PA12 temperature-memory fibers, for which a remarkable loss and shift in recovery stress were verified after slow deformation. ${ }^{43}$ However, the temperatures, at which strain and stress finally stabilized (Fig. 4a), corresponded to the recently determined DSC offset melting temperature of the PBA phase ${ }^{36}$ and were in analogy with the in situ WAXS data of untreated PEU (Fig. 1). Throughout the measurement series, the recovered strain $\varepsilon_{\mathrm{u}}-\varepsilon_{\mathrm{p}}$ and the maximum recovery stress $\sigma_{\text {max }}$ declined at higher $T_{\mathrm{d}}$ due to the increasing elasticity of the TMP at higher temperatures. In turn, the total strain recovery ratio $R_{\mathrm{r} \text {,tot }}$ remained permanently around $90 \%$.

In another attempt to gain control over the TME, the temperature holding time $t_{\mathrm{h}}$ at $T_{\mathrm{d}}$ was drastically extended. Similar as above, we started our examinations with the stressstrain behavior, but used a strain rate $\varepsilon^{\prime}$ of $3 \times 10^{2} \% \mathrm{~min}^{-1}$ (Fig. 6 and ESI Fig. 6 and $7 \dagger$ ). Once again, the whole programming history is exhibited in a stress-strain-temperature diagram (Fig. 6a). In essence, the tensile deformation behavior (Fig. 6b) was similar as expected. First of all, values for strain and stress at yield (ESI Fig. 6†) were in between those which could be determined when selecting a slower and a higher stain rate, respectively (ESI Fig. $3 \dagger$ ). Secondly, as can be seen in Fig. 6c, an extension of temperature holding time at $T_{\mathrm{d}}$ from $5 \mathrm{~min}$ to $15 \mathrm{~h}$ caused proceeding stress relaxation, which

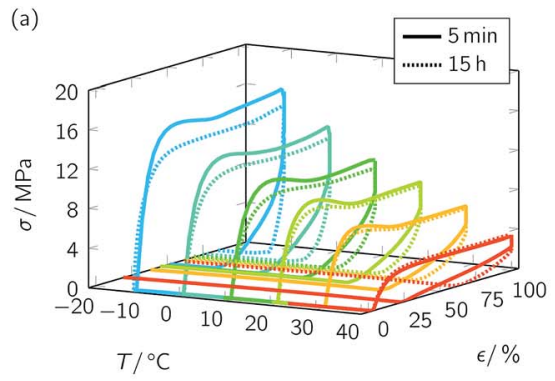

(c)

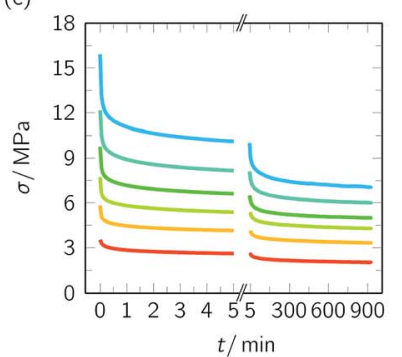

(b)

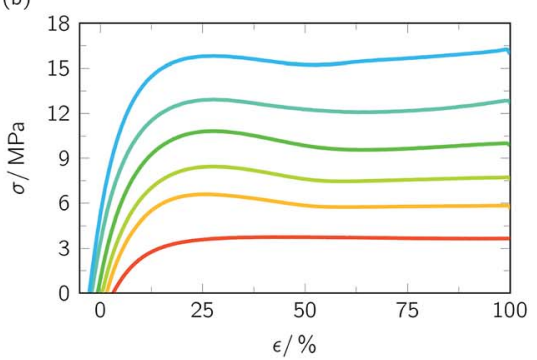

(d)

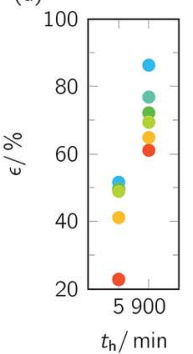

Fig. 6 Programming of various temperature-memory effects in PEU. Stress-strain-temperature protocol (a) and diagrams showing the stressstrain behavior during deformation ((b), $\left.\varepsilon^{\prime}=3 \times 10^{2} \% \mathrm{~min}^{-1}\right)$, stress relaxation behavior when keeping the specimens at $\varepsilon_{\mathrm{m}}=100 \%\left((\mathrm{c}), t_{\mathrm{h}}=5 \mathrm{~min}\right.$ and $15 \mathrm{~h}$ ) and nominal strain after unloading with $10 \% \mathrm{~min}^{-1}$ at $T_{\mathrm{d}}(\mathrm{d})$. The obtained Young's moduli $E$ were $217 \mathrm{MPa}\left(T_{\mathrm{d}}=-10^{\circ} \mathrm{C}\right), 156 \mathrm{MPa}\left(T_{\mathrm{d}}=\right.$ $\left.0{ }^{\circ} \mathrm{C}\right), 144 \mathrm{MPa}\left(T_{\mathrm{d}}=10^{\circ} \mathrm{C}\right), 107 \mathrm{MPa}\left(T_{\mathrm{d}}=20^{\circ} \mathrm{C}\right), 97 \mathrm{MPa}\left(T_{\mathrm{d}}=30^{\circ} \mathrm{C}\right)$ and $48 \mathrm{MPa}\left(T_{\mathrm{d}}=40^{\circ} \mathrm{C}\right)$. 
(a)

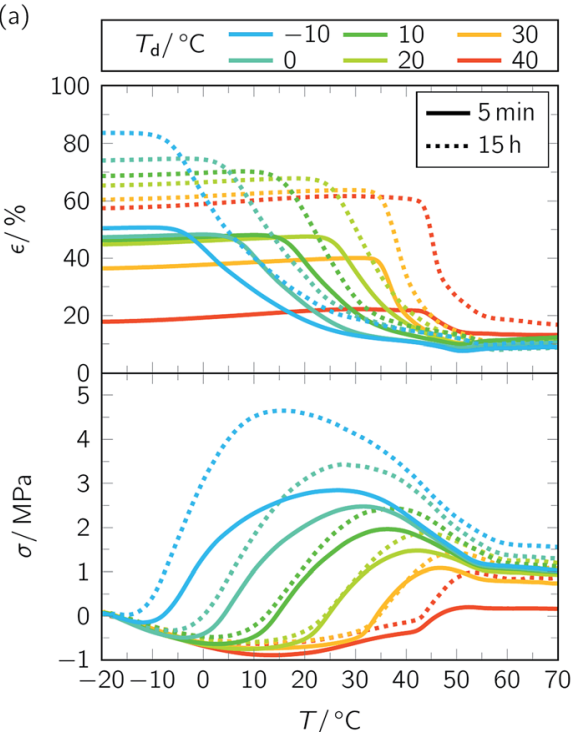

(b)

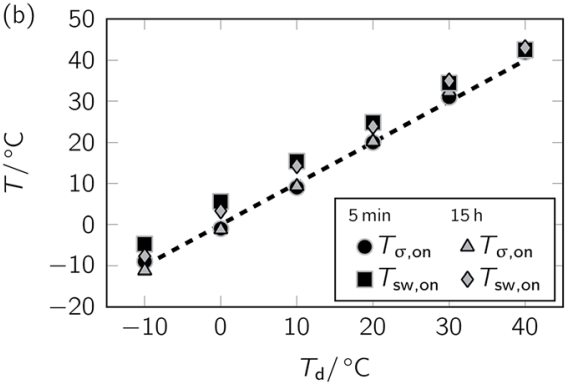

Fig. 7 Influence of temperature holding time $t_{\mathrm{h}}$ at $T_{\mathrm{d}}\left(\varepsilon=3 \times 10^{2} \%\right.$ $\mathrm{min}^{-1}$ ) on temperature-memory behavior of PEU. Consideration of 5 min ((a), solid lines; data were taken from a recent publication $\left.{ }^{36}\right)$ and 15 h ((a), dotted lines). Results of stress-free and constant strain recovery measurements (a) and evolution of $T_{\mathrm{sw}, \mathrm{on}}$ and $T_{\sigma, \mathrm{on}}$ with $T_{\mathrm{d}}$ (b).

was more pronounced at lower temperatures (ESI Fig. $7 \dagger$ ) and seemed to be accompanied by PBA crystallization. From programming one-way shape-memory effects in segmented polyurethanes it is well-known that elongated specimens show pronounced stress decline, which goes along with significant crystallization of the soft segment phase. ${ }^{61-64}$ To analyze the influence of temperature holding time at $T_{\mathrm{d}}$ on PBA crystallinity, further WAXS measurements were carried out (ESI Fig. $8 \dagger$ ). The experiments unveiled that drastic extension of $t_{\mathrm{h}}$ favored an increase in overall crystallinity $\chi_{\mathrm{c}}$ from $18.6 \%$ to $18.9 \%$ for $T_{\mathrm{d}}=$ $10{ }^{\circ} \mathrm{C}$ (ESI Fig. 8a ${ }^{\circ}$ ) and from $17.1 \%$ to $22.2 \%$ for $T_{\mathrm{d}}=40^{\circ} \mathrm{C}$ (ESI Fig. $8 \mathrm{~b} \dagger$ ). These higher fractions of stiff crystalline regions probably caused a reduction of chain mobility and therefore much higher strains after unloading (Fig. 6d). However, in agreement with the other measurement series (Fig. 4a), specimens exhibited distinct temperature-memory behavior when heated to $80^{\circ} \mathrm{C}$ as proven under stress-free and constant strain recovery conditions (Fig. 7, Table 2). As apparent in all measurements, the extension in $t_{\mathrm{h}}$ supported improved strain fixities $\left(R_{\mathrm{f}}\right.$ ratios) and strain recoverabilities $\left(\varepsilon_{\mathrm{u}}-\varepsilon_{\mathrm{p}}\right)$ while the impact on $R_{\mathrm{r} \text {,tot }}$ remained negligible (Table 2, Fig. 7a, above). Nominally, significant crystallization of the switching segment at $40{ }^{\circ} \mathrm{C}$ (ESI Fig. $8 \dagger$ ), for instance, led to gains in $R_{\mathrm{f}}$ ratio by $39 \%$ and in strain recoverability by $36 \%$. In this sense, isothermal crystallization turned useful to enhance control both over the fixed and recovered strain, even at a temperature, at which strain rate variation remained without impact. Since the experimental findings were always based on the same maximum strain applied $\left(\varepsilon_{\mathrm{m}}=100 \%\right)$ and due the fact that the programming route allowed for temperature-memory onset control (Fig. 7a), ${ }^{36}$ an unprecedented fine-tuning of thermoresponsiveness could be achieved for a TMP under stress-free recovery conditions. Under constant strain recovery conditions, preceding PBA crystallization during programming counteracted specimen relaxation, thus favoring substantially superior maximum recovery stresses $\sigma_{\max }$ in the ensuing heating run (Fig. 7a, below). A similar trend, namely a rise in contracting force with growing crystallinity content, is known from structurally related polyurethane-based shape memory polymers. ${ }^{11,22,65}$ Thus, extension of $t_{\mathrm{h}}$ at $T_{\mathrm{d}}$ supported a different material behavior compared to CNT-PA12 composite fibers, for

Table 2 Influence of temperature holding time $t_{\mathrm{h}}$ at $T_{\mathrm{d}}\left(\varepsilon^{\prime}=3 \times 10^{2} \% \mathrm{~min}^{-1}\right)$ on temperature-memory properties of PEU. Data for the $5 \mathrm{~min}$ measurements were taken from a recent publication. ${ }^{36}$ Errors were estimated from repeated measurements

\begin{tabular}{|c|c|c|c|c|c|c|c|c|c|c|}
\hline \multirow[b]{2}{*}{$\underline{T_{\mathrm{d}}\left({ }^{\circ} \mathrm{C}\right)}$} & \multirow[b]{2}{*}{$t_{\mathrm{h}}(\min )$} & \multirow[b]{2}{*}{$R_{\mathrm{f}}(\%)$} & \multicolumn{4}{|c|}{ Stress-free recovery conditions } & \multicolumn{4}{|c|}{ Constant strain recovery conditions } \\
\hline & & & $R_{\mathrm{r}, \text { tot }}(\%)$ & $\varepsilon_{\mathrm{u}}-\varepsilon_{\mathrm{p}}(\%)$ & $T_{\mathrm{sw}, \text { on }}\left({ }^{\circ} \mathrm{C}\right)$ & $T_{\mathrm{sw}, \text { off }}\left({ }^{\circ} \mathrm{C}\right)$ & $T_{\sigma, \text { on }}\left({ }^{\circ} \mathrm{C}\right)$ & $T_{\sigma, \max }\left({ }^{\circ} \mathrm{C}\right)$ & $T_{\sigma, \text { off }}\left({ }^{\circ} \mathrm{C}\right)$ & $\sigma_{\max }(\mathrm{MPa})$ \\
\hline 0 & 5 & $47 \pm 2$ & $89 \pm 3$ & $36 \pm 3$ & $6 \pm 1$ & $48 \pm 3$ & $-1 \pm 2$ & $32 \pm 2$ & $54 \pm 2$ & $2.5 \pm 0.2$ \\
\hline 10 & 5 & $46 \pm 2$ & $87 \pm 3$ & $33 \pm 3$ & $15 \pm 1$ & $49 \pm 3$ & $9 \pm 2$ & $36 \pm 2$ & $54 \pm 2$ & $2.0 \pm 0.2$ \\
\hline 20 & 5 & $45 \pm 2$ & $88 \pm 3$ & $33 \pm 3$ & $25 \pm 1$ & $50 \pm 3$ & $20 \pm 2$ & $43 \pm 2$ & $54 \pm 2$ & $1.5 \pm 0.2$ \\
\hline-10 & 900 & $84 \pm 3$ & $89 \pm 2$ & $73 \pm 3$ & $-8 \pm 1$ & $54 \pm 2$ & $-11 \pm 1$ & $15 \pm 2$ & $58 \pm 2$ & $4.7 \pm 0.2$ \\
\hline 0 & 900 & $74 \pm 3$ & $91 \pm 2$ & $65 \pm 3$ & $3 \pm 1$ & $57 \pm 2$ & $-1 \pm 1$ & $28 \pm 2$ & $58 \pm 2$ & $3.4 \pm 0.2$ \\
\hline 10 & 900 & $69 \pm 3$ & $89 \pm 2$ & $58 \pm 3$ & $14 \pm 1$ & $56 \pm 2$ & $9 \pm 1$ & $39 \pm 2$ & $59 \pm 2$ & $2.4 \pm 0.2$ \\
\hline 20 & 900 & $65 \pm 3$ & $89 \pm 2$ & $54 \pm 3$ & $24 \pm 1$ & $55 \pm 2$ & $20 \pm 1$ & $44 \pm 2$ & $59 \pm 2$ & $1.9 \pm 0.2$ \\
\hline 30 & 900 & $60 \pm 3$ & $90 \pm 2$ & $50 \pm 3$ & $35 \pm 1$ & $56 \pm 2$ & $32 \pm 1$ & $50 \pm 2$ & $59 \pm 2$ & $1.4 \pm 0.2$ \\
\hline 40 & 900 & $57 \pm 3$ & $84 \pm 2$ & $41 \pm 3$ & $43 \pm 1$ & $56 \pm 2$ & $43 \pm 1$ & $53 \pm 2$ & $60 \pm 2$ & $1.0 \pm 0.2$ \\
\hline
\end{tabular}


which ongoing storage time at $T_{\mathrm{d}}$ resulted in a decrease in $\sigma_{\max }$, culminating in an entire loss of temperature-memory behavior. ${ }^{43}$ Incidentally, a $\sigma_{\max }$ of $4.7 \mathrm{MPa}$ was recorded for the PEU when deformed at $-10{ }^{\circ} \mathrm{C}$; it was the highest maximum recovery stress compared with the other semicrystalline TMPs investigated so far. ${ }^{3,35}$

Finally, it is worth underlining that variation of temperature holding time did not significantly impart the transition temperatures. Same as in the first measurement series (Fig. 4b), recovery temperatures $T_{\mathrm{sw}, \text { on }}$ and $T_{\sigma \text {,on }}$ increased almost linearly with $T_{\mathrm{d}}$ over the whole temperature range investigated (Fig. 7b). In contrast to TMPs, whose switching segments are vitrified during programming and for which relaxation effects may lead to a loss of temperature-memory information as exemplified by an increase in strain recovery temperature with ongoing temperature holding time at $T_{\mathrm{d}},{ }^{6}$ strain fixing through crystallization did not shift the recovery temperature. Thus, the shape fixing and switching mechanism proved once more to be reliable.

\section{Conclusions}

Modification of programming parameters like strain rate and temperature holding time at $T_{\mathrm{d}}$ provided a facile strategy to gain precise control over the temperature-memory behavior of semicrystalline polyurethane. Slow loading favored straininduced crystallization of the switching segment, rapid deformation resulted in necking, specimen heating and significant crystallization. Both allowed designing TMEs under stress-free recovery conditions. Although identified as thermoreversible phenomenon, necking seemed to account for a slight reduction in maximum recovery stress. Apart from that, it became clear that not all TMPs lose memory with age; this behavior seems rather to be limited to the amorphous ones. ${ }^{43}$ In particular, the extension of temperature holding time at $T_{\mathrm{d}}$ did not allow temperature-memory amnesia for semicrystalline TMP, but was the key to strongly improve the material behavior. The associated gain in crystallinity enabled significantly higher strain fixities, strain recoverabilities and maximum recovery stresses. Basically, programming-assisted tailoring of TMEs can also be understood as tool to optimize material behavior according user-defined needs. This could stimulate innovation, e.g. in applications like thermo-sensitive grippers, sensing elements and information carriers.

\section{Acknowledgements}

The research has been carried out with the support of the German Federal Ministry of Education and Research (BMBF, project funding reference number 16V0043). N. M. thanks Manfred Wagner for fruitful discussions. The authors express their gratitude to Maren Erdmann for carrying out thermomechanical measurements, Franziska Emmerling and Ralf Bienert for their advice and help regarding the WAXS measurements and Christiane Maierhofer and Mathias Röllig for IR thermographic measurements. The authors acknowledge Bayer MaterialScience AG for kindly providing the PEU.

\section{References}

1 P. Miaudet, A. Derré, M. Maugey, C. Zakri, P. M. Piccione, R. Inoubli and P. Poulin, Science, 2007, 318, 12941296.

2 L. Sun and W. M. Huang, Soft Matter, 2010, 6, 4403-4406.

3 K. Kratz, S. A. Madbouly, W. Wagermaier and A. Lendlein, Adv. Mater., 2011, 23, 4058-4062.

4 L. Wang, S. Di, W. Wang, H. Chen, X. Yang, T. Gong and S. Zhou, Macromolecules, 2014, 47(5), 1828-1836.

5 Y. Wang, J. Li, X. Li, Y. Pan, Z. Zheng, X. Ding and Y. Peng, RSC Adv., 2014, 4(39), 20364-20370.

6 K. Yu and H. J. Qi, Soft Matter, 2014, 10(47), 9423-9432.

7 B. K. Kim, S. Y. Lee and M. Xu, Polymer, 1996, 37(26), 57815793.

8 F. K. Li, J. N. Hou, W. Zhu, X. Zhang, M. Xu, X. L. Luo, D. Z. Ma and B. K. Kim, J. Appl. Polym. Sci., 1996, 62(4), 631-638.

9 F. Li, X. Zhang, J. Hou, M. Xu, X. Luo, D. Ma and B. K. Kim, J. Appl. Polym. Sci., 1997, 64(8), 1511-1516.

10 B. S. Lee, B. C. Chun, Y.-C. Chung, K. I. Sul and J. W. Cho, Macromolecules, 2001, 34, 6431-6437.

11 P. Ping, W. Wang, X. Chen and X. Jing, Biomacromolecules, 2005, 6, 587-592.

12 W. Wang, P. Ping, X. Chen and X. Jing, Eur. Polym. J., 2006, 42(6), 1240-1249.

13 S. Chen, J. Hu, Y. Liu, H. Liem, Y. Zhu and Y. Liu, J. Polym. Sci., Part B: Polym. Phys., 2007, 45(4), 444-454.

14 J. D. Merline, C. P. R. Nair, C. Gouri, R. Sadhana and K. N. Ninan, Eur. Polym. J., 2007, 43, 3629-3637.

15 T. S. Wilson, J. P. Bearinger, J. L. Herberg, J. E. Marion III, W. J. Wright, C. L. Evans and D. J. Maitland, J. Appl. Polym. Sci., 2007, 106(1), 540-551.

16 S. D'Hollander, G. Van Assche, B. Van Mele and F. Du Prez, Polymer, 2009, 50(19), 4447-4454.

17 J. Han, B. Chen, L. Ye, A.-Y. Zhang, J. Zhang and Z.-G. Feng, Front. Mater. Sci. China, 2009, 3(1), 25-32.

18 L. Xue, S. Dai and Z. Li, Macromolecules, 2009, 42(4), 964972.

19 M. Ahmad, J. Luo, B. Xu, H. Purnawali, P. J. King, P. R. Chalker, Y. Fu, W. Huang and M. Miraftab, Macromol. Chem. Phys., 2011, 212, 592-602.

20 I. M. Pereira and R. L. Oréfice, Macromol. Symp., 2011, 299300, 190-198.

21 A. Petchsuk, W. Klinsukhon, D. Sirikittikul and C. Prahsarn, Polym. Adv. Technol., 2012, 23(8), 1166-1173.

22 M. Bothe, F. Emmerling and T. Pretsch, Macromol. Chem. Phys., 2013, 214(23), 2683-2693.

23 T. Pretsch, Smart Mater. Struct., 2010, 19(1), 015006.

24 M. Bothe and T. Pretsch, Macromol. Chem. Phys., 2012, 213(22), 2378-2385.

25 A. Lendlein and S. Kelch, Angew. Chem., Int. Ed., 2002, 41(12), 2034-2057.

26 P. T. Mather, X. Luo and I. A. Rousseau, Annu. Rev. Mater. Res., 2009, 39(1), 445-471.

27 T. Pretsch, Polymers, 2010, 2(3), 120-158. 
28 J. Leng, X. Lan, Y. Liu and S. Du, Prog. Mater. Sci., 2011, 56(7), 1077-1135.

29 H. Lu, Soft Matter, 2013, 9(47), 11157-11158.

30 H. Lu and W. M. Huang, Smart Mater. Struct., 2013, 22(10), 105021.

31 H. Lu, Y. Yao and L. Lin, Pigm. Resin Technol., 2015, 44(2), 94-100.

32 K. K. Julich-Gruner, C. Löwenberg, A. T. Neffe, M. Behl and A. Lendlein, Macromol. Chem. Phys., 2013, 214(5), 527-536.

33 G. J. Berg, M. K. McBride, C. Wang and C. N. Bowman, Polymer, 2014, 55(23), 5849-5872.

34 T. Xie, K. A. Page and S. A. Eastman, Adv. Funct. Mater., 2011, 21(11), 2057-2066.

35 K. Kratz, U. Voigt and A. Lendlein, Adv. Funct. Mater., 2012, 22(14), 3057-3065.

36 N. Fritzsche and T. Pretsch, Macromolecules, 2014, 47(17), 5952-5959.

37 L. Viry, C. Mercader, P. Miaudet, C. Zakri, A. Derré, A. Kuhn, M. Maugey and P. Poulin, J. Mater. Chem., 2010, 20, 34873495.

38 T. Xie, Nature, 2010, 464(10), 267-270.

39 R. Xiao, J. Guo and T. Nguyen, RSC Adv., 2015, 5(1), 416-423.

40 J. Cui, K. Kratz and A. Lendlein, Smart Mater. Struct., 2010, 19(6), 065019.

41 J. Li, T. Liu, S. Xia, Y. Pan, Z. Zheng, X. Ding and Y. Peng, J. Mater. Chem., 2011, 21, 12213-12217.

42 C. Samuel, S. Barrau, J.-M. Lefebvre, J.-M. Raquez and P. Dubois, Macromolecules, 2014, 47(19), 6791-6803.

43 F. Grillard, C. Zakri, P. Gaillard, A. Korzhenko, W. Néri and P. Poulin, Soft Matter, 2014, 10(44), 8985-8991.

44 J. Hättig, W. Bräuer and T. Pretsch, Kunststoffe, 2013, 1(1), 39-41.

45 T. Pretsch, M. Ecker, M. Schildhauer and M. Maskos, J. Mater. Chem., 2012, 22(16), 7757-7766.

46 N. Fritzsche and T. Pretsch, ASME Conf. Smart Mater., Adapt. Struct. Intell. Syst., Proc., 2012, 1, 81-88.

47 M. Ecker and T. Pretsch, $R S C A d v ., 2014,4(1), 286-292$.
48 M. Ecker and T. Pretsch, RSC Adv., 2014, 4(87), 46680-46688. 49 DIN EN ISO 527-2:1996, Plastics - Determination of tensile properties.

50 K.-H. Nitta and H. Nomura, Polymer, 2014, 55(25), 66146622.

51 O. Paris, C. Li, S. Siegel, G. Weseloh, F. Emmerling, H. Riesemeier, A. Erko and P. Fratzl, J. Appl. Crystallogr., 2007, 40(3), 466-470.

52 A. P. Hammersley, S. O. Svensson, M. Hanfland, A. N. Fitch and D. Hausermann, High Pressure Res., 1996, 14(4-6), 235-248.

53 M. Bothe and T. Pretsch, J. Mater. Chem. A, 2013, 1(46), 14491-14497.

54 M. Bothe, K. Y. Mya, E. M. J. Lin, C. C. Yeo, X. Lu, C. He and T. Pretsch, Soft Matter, 2012, 8(4), 965-972.

55 W. M. Huang, H. B. Lu, Y. Zhao, Z. Ding, C. C. Wang, J. L. Zhang, L. Sun, J. Fu and X. Y. Gao, Mater. Des., 2014, 59(7), 176-192.

56 J. W. Maher, R. N. Haward and J. N. Hay, J. Polym. Sci., Polym. Phys. Ed., 1980, 18(11), 2169-2179.

57 S. L. Bazhenov and A. S. Kechek'yan, J. Polym. Sci., Part A: Polym. Chem., 2013, 55(6), 404-414.

58 M. A. Guseva, V. A. Gerasin, O. K. Garishin, V. V. Shadrin, O. A. Plekhov and A. Pawlak, Polymer, 2015, 56(1), 416-427.

59 J. Gough, Philos. Mag., 1806, 24(93), 39-43.

60 E. Pink, A. Kronthaler and P. Valtingoier, J. Mater. Sci., 1989, 24(1), 183-186.

61 F. L. Ji, J. L. Hu, T. C. Li and Y. W. Wong, Polymer, 2007, 48(17), 5133-5145.

62 T. Pretsch, I. Jakob and W. Müller, Polym. Degrad. Stab., 2009, 94(1), 61-73.

63 T. Pretsch and W. Müller, Polym. Degrad. Stab., 2010, 95(5), 880-888.

64 W. Müller and T. Pretsch, Eur. Polym. J., 2010, 46(8), 17451758.

65 K. Y. Mya, H. B. Gose, T. Pretsch, M. Bothe and C. He, J. Mater. Chem., 2011, 21(13), 4827-4836. 